\title{
correspondence
}

\section{Synchrotron radiation facility}

SiR,-After reading the article by John Gribbin (Nature, April 12) on the proposal for a new synchrotron radiation facility, I am wondering if he and I went to the same meeting. Certainly the meeting $\mathrm{I}$ attended did not show clearly that the proposal to build a new $£ 2$ million storage ring "needs careful rethinking" or that "the plan as originally envisaged seems unlikely to survive". At the conclusion of the meeting, the physicists, chemists, biologists and metallurgists present made it overwhelmingly clear that they firmly supported the existing SRC plans.

The project is not at the early stages of planning. Indeed, the scientific case for a dedicated storage ring has been established over a considerable period of time, accepted by the Science Board of SRC and a design study costing $£ 70,000$ is already well under way.

Storage ring facilities being built in Hamburg and Paris are such that synchrotron radiation users will have limited access and remain parasitic. What is envisaged in the United Kingdom is a unique facility, with 10 access points and accommodating 30 experiments simultaneously. Many experiments which could not previously be performed due to lack of intensity now become feasible. New experiments utilising the polarisation properties of synchrotron radiation have been proposed, and the enormous flux in the $1 \AA$ region will allow time resolution of milliseconds or better in the study of complex biological functions, such as muscle flexing. The storage ring is also expected to be a potent source for scattering experiments below $1 \AA$.

What the scientists present at Reading were extremely concerned about was the time scale involved in building a dedicated storage ring. The building of such a facility could in principle be started almost immediately because no major new technological advances are envisaged (I omit consideration about the "wigglers" required to reach the shorter wavelengths). It need not be built at Daresbury and therefore need not await the closure of NINA. This would ensure that the United Kingdom has its share of new and exciting physics. Is it realistic, however, to suggest such an alternative? The estimated cost of $£ 2$ million would raise, since a new building to house the storage ring, and all the services available in the NINA facility, would have to be provided. Incidentally, Professor Bleaney's suggestion of a disastrous 5 year period between NINA closure and storage ring commissioning was refuted by Daresbury personnel present. A preliminary estimate is 12 to 18 months, given the level of funding shown in the SRC document. This could be reduced with sufficient manpower and money if SRC were to give whole-hearted support to the proposal.

It is now up to the SRC to act swiftly and decisively in this matter or the United Kingdom will once again find itself an also-ran in the race for scientific discovery. The critics have had their chance to comment on the proposal and no substantial argument was forthcoming. (For example, nobody has suggested that a tunable soft X-ray laser will turn such a facility into an under-used white elephant.) In the absence of such criticism, let us press ahead with a facility whioh will surely be the envy of synchrotron radiation users throughout the world. Yours faithfully, K. Codling

J. J. Thomson Physical Laboratory, Whiteknights, Reading RG6 $2 A F$

We have also received another letter in similar vein from seventeen of those at the Reading meeting.--ED.

\section{Penicillin}

SIR,-I am grateful to Ernst Chain for his comments on the rediscovery of penicillin (Nature, June 14). There would, however, seem to be ample justification in the literature for the viewpoint I put forward in my earlier article (Nature, May 24) concerning the direction of research into antibiotics during wartime and the quest for agents of chemotherapy. Chain's first joint paper in the field ${ }^{\mathrm{l}}$ refers to chemotherapy in title and substance, and his later joint publication that same year (on penicillinase) discusses the relative merits of penicillin as an agent of chemotherapy". The extensive paper on therapy using penicillin published some months later by Chain and the other members of the Oxford team ${ }^{3}$ expands on the theme. The effects of the war effort, to which I have referred elsewhere ${ }^{4}$ is repeatedly emphasised in Fleming's classic volume ${ }^{5}$ (to which, apparently, the Oxford workers declined to contribute). Bacharac and $\mathrm{Hems}^{6}$ in particular, state that penicillin seemed to "merit much more attention than it had received", a pointer to exactly the form of directed research I would like to see in oncology. It contrasts radically with Coghill's comments $^{7}$ that Raistrick, apparently the first to see the significance of antibiotics, "could get no clinical tests made". Perhaps the essence of what we should say is that, though it is widely assumed that Fleming's fortuitous discovery gave rise to the concept of antibiosis, the discovery of Penicillium notatum, and the first recorded examples of 'microbial therapy', it did not in fact originate any of these ${ }^{8}$. In this respect the researc work of Howard Florey and Ernst Chain, with their coworkers, was of peerless importance.

Yours faithfully,

BRIAN J. FORD

\section{Cardiff}

"Chain, E., Florey, H. W., Gardner, A. D., Heatley, N. G., Jennings, M. A., Orr-Ewing, J., and Sanders, A. G., Lancet, ii, 226-228 (1940).

2 Abraham, E. P., and Chain, E., Nature, 146, 837 (1940).

${ }^{3}$ Abraham, E. P., Chain, E., Fletcher, C. M., Florey, H. W., Gardner, A. D., Heatley, N. G., and Jennings, M. A.. Lancet, ii, 177-189 (1941).

4 Ford, Brian J., History of the Second World War, 2851-2857 (Purnell, London, 1968).

"Penicillin, its practical application (edit. by Fleming, A.) (Butterworth, London, 1946).

${ }^{6}$ Bacharach, A. L., and Hems, B. A., ibid., 24-45.

${ }^{7}$ Coghili, R. D., Chem. Engng News, 22. 588 .

"Ford, Brian J., The Revealing Lens: Mankind and the Microscope, 130135 (Harrap, London, 1973).

\section{Wursted}

SiR, - We are not in complete agreement with Neidle's point (Nature, 249, $212 ; 1974)$ that there is a cultural bias in the understanding of our "hotdog" model for repressor-operator interaction. The Germans, for example, might consider it the Wurst model of operator-repressor binding. Yours faithfully,

$$
\begin{aligned}
& \text { T. A. STEITZ } \\
& \text { B. ENGElman }
\end{aligned}
$$

Yale University,

New Haven, Connecticut 06520

The briefer the letter the better its chance of being published. We reserve the right to cut correspondence. 